\title{
Intelligent Model for Fault Detection on Geothermal Exchanger of a Heat Pump
}

\author{
José Luis Casteleiro-Roca ${ }^{1}$, Héctor Quintián ${ }^{1}$, José Luis Calvo-Rolle ${ }^{1}$, Emilio \\ Corchado $^{2}$ and María del Carmen Meizoso-López ${ }^{1}$ \\ 1 Universidad de A Coruña, \\ Departamento de Ingeniería Industrial, \\ Avda. 19 de febrero s/n, 15.495, Ferrol, A Coruña, España \\ 2 Universidad de Salamanca, \\ Departamento de Informática y Automática, \\ Plaza de la Merced s/n, 37.008, Salamanca, Salamanca, España
}

\begin{abstract}
The Heat Pump with geothermal exchanger is one of the best methods to heat a building. The heat exchanger is an element with probabilities of failure due its size and due it is outside construction. The present study shows a novel intelligent system design to detect faults on this type of heating equipment. The novel approach has been successfully empirically tested under a real dataset obtained during measurements along one year. It is based on classification techniques with the aim to detect failures in real time. Then the model is validated and verified over the building; it allows to obtain good results in all the operating conditions ranges.
\end{abstract}

Keywords: MLP, J48, FLDA, Heat Exchanger, Heat Pump, Geothermal Exchanger

\section{Introduction}

A Heat Pump provides heat by taking out it from a source, and then transferring it into a house [1]. Heat can be obtained from any source, whether it is cold of heat. But if this source is warm then it is possible to achieve higher efficiency [2]. The ground can be a source for the Heat Pump and, the heat exchangers topology can be vertical or horizontal $[1,3]$. Usually horizontal exchanger is more economical than the vertical configuration [3]; however this configuration has less efficiency than the other one. With the aim to increase the performance of the horizontal exchanger, frequently, installers place the exchanger more deeply in the ground [4].

Both configurations, vertical and horizontal have their own operation problems, but the horizontal has more inconvenient than the other, among others because the exchanger is closer to the ground surface $[5,6]$. Due to the proximity to the surface, the weather has influence over the exchanger and the efficiency could be lower $[7,8]$. For the same reason the installation may be damaged due 
to different reasons like crushing, perforations, and so on [9]. In normal, the performance is the same during throughout the year, but if any problem appears, then, the efficiency could drop significantly or even stop working [5].

Fault detection involves the monitoring of a system and the detection when a fault has occurred [10]. The system must be modeled or a knowledge based system must be created with the aim to detect deviations of the correct performance [11]. There are typical systems where fault detection has been implemented with satisfactory results. For instance, [12] propose a two-stage recognition system for continuous analysis of ElectroEncephaloGram (EEG) signals. [13] proposes a model-based Robust Fault Detection and Isolation (RFDI) method with hybrid structure. In [14] is presented a fault detection strategy for wireless sensor networks. In [15] a hybrid two stage one-against-all Support Vector Machine (SVM) approach is proposed for the automated diagnosis of defective rolling element bearings, [16] shows the robust fault detection problem for non-linear systems considering both bounded parametric modeling errors and measurement noises. As can be seen on the mentioned examples of fault detection, different soft computing techniques have been used to solve the problem.

This research presents a new intelligent method to make fault detection on buildings for a Heat Pump system using geothermal exchanger. The way to detect wrong work-points of operation is creating a model based on classification. This model has been trained with a big dataset of a year of operation, and consequently all weather seasons are taking into account. The model was tested with a real dataset of failures samples obtained for this purpose.

This paper is organized as follows. It begins with a brief description of the case of study followed by an explanation of the model approach and the dataset conditioning to perform fault detection through classification techniques. In the next section results are presented, and finally the conclusions and future work are exposed.

\section{Case of study}

The novel model has been applied to do fault detection in a Geothermical Heat Pump. It is part of the systems installed within a real bioclimatic house. The physical system is described in detail as follows.

\subsection{Sotavento bioclimatic house}

Sotavento bioclimatic house is a project of demonstrative bioclimatic house of Sotavento Galicia Foundation. The house is located within the Sotavento Experimental Wind Farm, which is a center of dissemination of renewable energy and energy saving. The farm is located between the councils of Xermade (Lugo) and Monfero (A Coruña), in the autonomous community of Galicia (Spain). It is at coordinates $43^{\circ} 21^{\prime}$ North, $7^{\circ} 52^{\prime}$ West, at an elevation of $640 \mathrm{~m}$ above sea level and at a distance of $30 \mathrm{Km}$ from the sea. Figure 1 shows geographic location in the Spanish territory (left), and an external view of the bioclimatic house (right). 

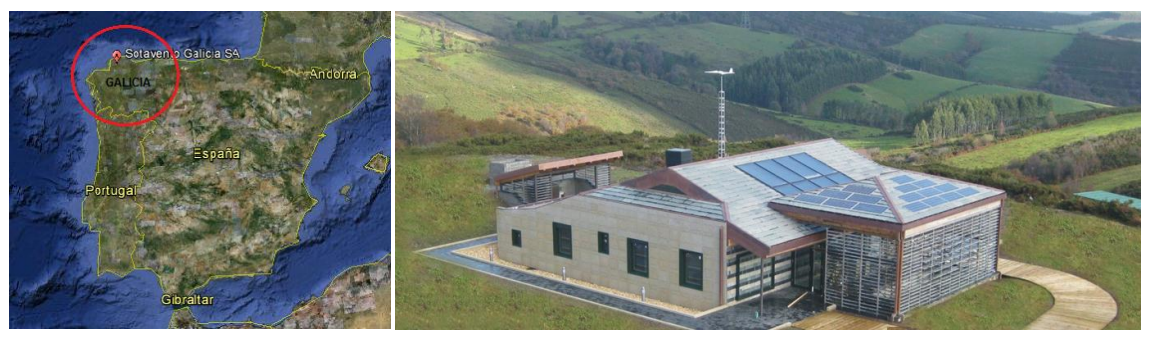

Fig. 1. Left: Geographic location of the bioclimatic house. Right: External view of the bioclimatic house

\subsection{Installations of the bioclimatic house}

Thermal and electrical installations of the bioclimatic house have various renewable energy systems to complement these installations. Figure 2 describes through a schema, the main systems and component of thermal and electrical installations. The thermal installation consists of 3 renewable energy systems (solar, biomass and geothermal) that serve the DHW (Domestic Hot Water) system and the heating system. The electrical installation consists of two renewable energy systems (wind and photovoltaic) and one connection to the grid power, getting supply to the lighting and power systems of the house.

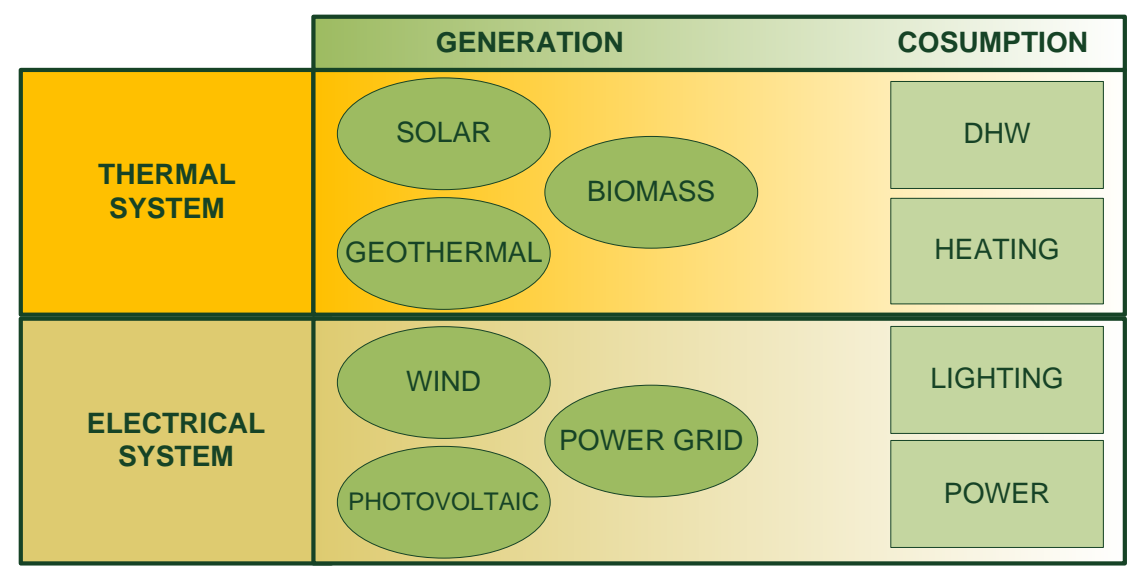

Fig. 2. Thermal and electrical installations of the house 


\subsection{Description of the thermal installation}

Figure 3 shows through a block diagram, the different components of the thermal installation and their interconnections. Overall, the heating installation can be divided into 3 functional groups:

- Generation group: Solar thermal (1), biomass boiler (2) and geothermal (3).

- Energy accumulation group: Inertial accumulator (5), solar accumulator (4) and preheating (8).

- Consumption group: Underfloor heating (6) and DHW (7).

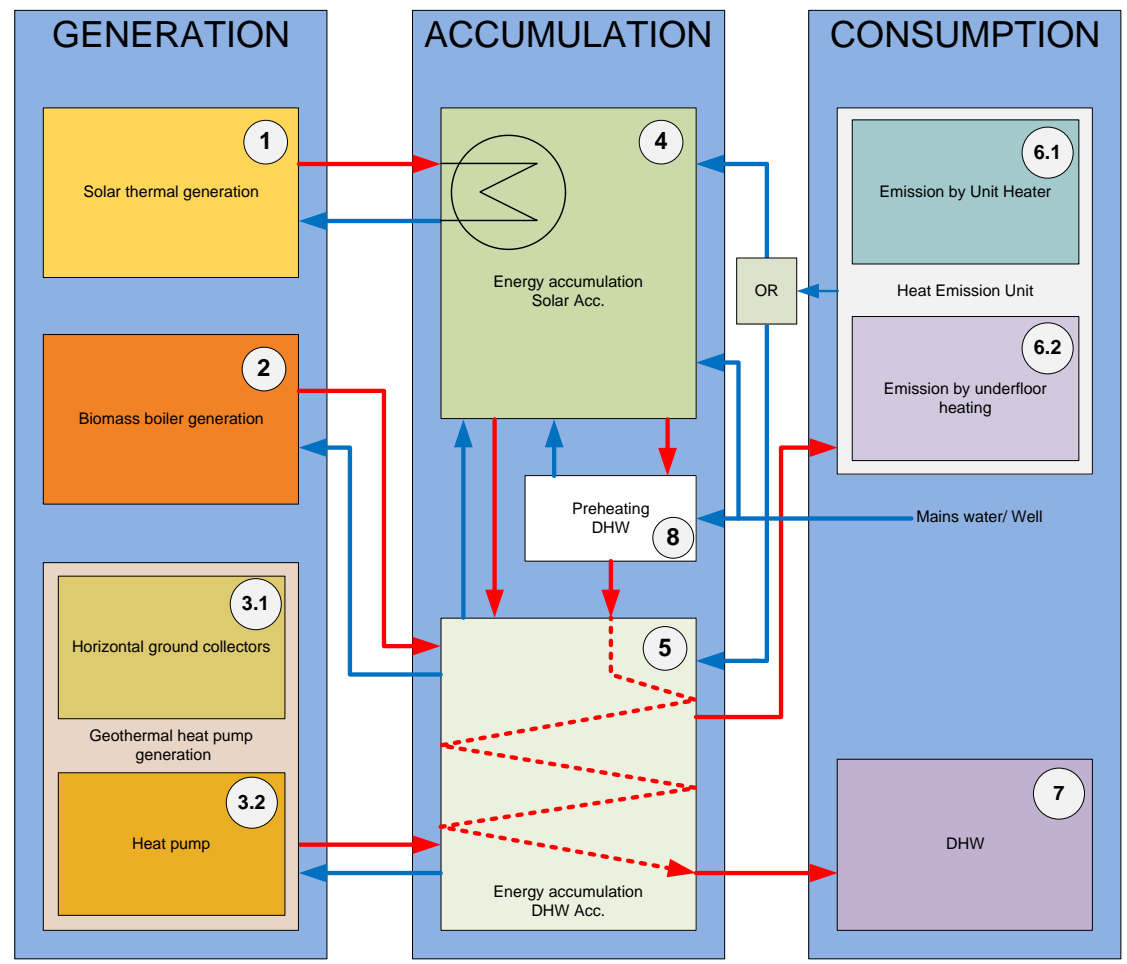

Fig. 3. Block diagram of the thermal systems installed in the bioclimatic house

Following each functional group is described in more detail.

Generation. The generation group has three collection systems of renewable energy:

- Solar thermal system: It consists of eight solar panels that capture energy from the solar radiation and use it to heat a fluid (ethyleneglycol) that flows 
inside the panels. The heated fluid is transported to the accumulation zone, where through the heat exchanger of the solar accumulator (4) gives up its heat to water stored inside the accumulator, getting to raise the water temperature for later use.

- Biomass boiler system: It has a biomass boiler type Ökofen, model Pallematic 20 , with adjustable power from $7 \mathrm{~kW}$ to $20 \mathrm{~kW}$, with a yield of pellets of $90 \%$. It gives the hot water directly to the inertial accumulator to $63^{\circ} \mathrm{C}$.

- Geothermal system: The system consists of a horizontal collector with 5 loops of 100 meters, each one buried at a depth of 2 meter and a Heat Pump with a nominal heating power of $8.2 \mathrm{~kW}$ with a nominal electrical power consumption of $1.7 \mathrm{~kW}$. It is possible to extract energy of the ground that is used to heat a fluid (water with glycol) that heats the water by geothermal pump and is driven directly to the inertial accumulator.

Accumulation. The system has a solar accumulator with storage capacity of 1000 liters which receives energy contribution of solar thermal system. This accumulator is connected in series with the inertia accumulator that has storage capacity of 800 liters, also it receives energy from the biomass boiler and geothermal system. The use of inertial accumulators is generally recommended in all types of heating systems and its function is to work as thermal energy storage to minimize starts and stops of the boiler.

Consumption. The house is equipped with DHW and underfloor heating systems, both supplied through the inertial accumulator. The DHW system has been sized based on the Spanish Technical Building Code, taking into account that the house only has a bathroom and a kitchen for demonstration purposes. Thus, the DHW system obtained was sized for 240 liters per day. The underfloor heating system consists of a network of crosslinked polyethylene with barrier etilvinil-alcohol (EVAL) pipes at a distance of $5 \mathrm{~cm}$ below the floor of the rooms of the house. It has 4 distribution collectors above the floor to enable the purging. This system is able to maintain the temperature inside the house between $18^{\circ} \mathrm{C}$ and $22^{\circ} \mathrm{C}$ for which the water circuit should only be between $35^{\circ} \mathrm{C}$ y $40^{\circ} \mathrm{C}$.

\subsection{Geothermal system under study}

This section gives a detailed description of the operation of the real geothermal system and its components.

System description. The Heat Pump is a MAMY Genius - $10.3 \mathrm{~kW}$ with a horizontal heat exchanger as is shown in figure 4 .

This study is only focussed on the two sensors shown in figure 4 (thick arrows), in the primary circuit of the Heat Pump. The Heat Pump have two different circuits; the primary one provides the heat from the ground (the exchanger), and the other one is connected to the inertial accumulator.

Geothermal exchanger. The horizontal exchanger has four different circuits, with the aim to isolate parts in case of discover a failure in one circuit. The installation has several temperature sensors installed along the heat exchanger to study the ground temperature while the system is running (figure 5 shows 


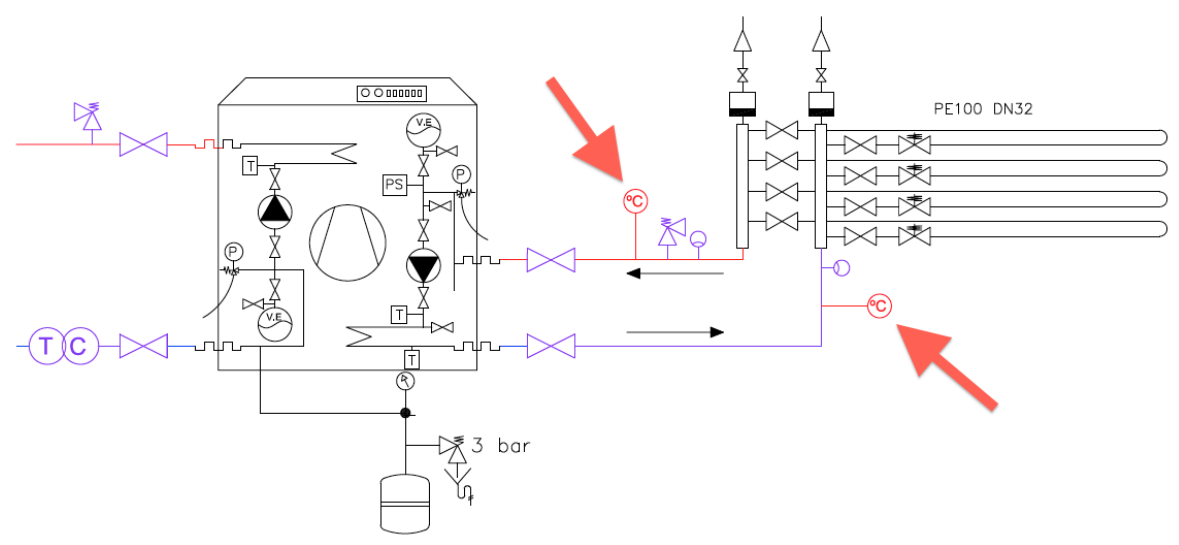

Fig. 4. Heat Pump and horizontal exchanger layout

the exchanger, and its connection to the house). The four circuits are connected all together outside the house and only one pipe goes to the Heat Pump (one output and one input of the exchanger).

\section{Model approach}

The fault detection model is based on the temperature difference at the output of the heat exchanger. These temperatures are measured at the Heat Pump. This is an improvement of the method, because it is not necessary to install sensors outside the building.

The model have three inputs. The first one is to indicate the state of the Heat Pump (on or off). The other two inputs are the temperatures at the input and at the output of the heat exchanger (figure 6).

\subsection{Obtaining and conditioning dataset}

The real dataset has been obtained by measurements taken along one year. Each measure has been taken every ten minutes.

Figure 7 shows the 144 measures of a day (one every 10 minutes). In this figure, Frame A shows a complete running cycle. Frame B is the part of the cycle when the Heat Pump is on, and Frame $\mathrm{C}$ is the restoration of the temperatures after the system turn off. In Frame D appears a cycle when the Heat Pump is off more time, and it is possible to see that the difference of the temperatures achieved more or less is the same.

$$
\Delta T=T_{\text {output }}-T_{\text {input }}
$$

The model studies the variation of the temperature ratio from the input to the output of the Heat Pump (equation 1). If the Heat Pump is running or not, the model tolerate more or less changes, then: 


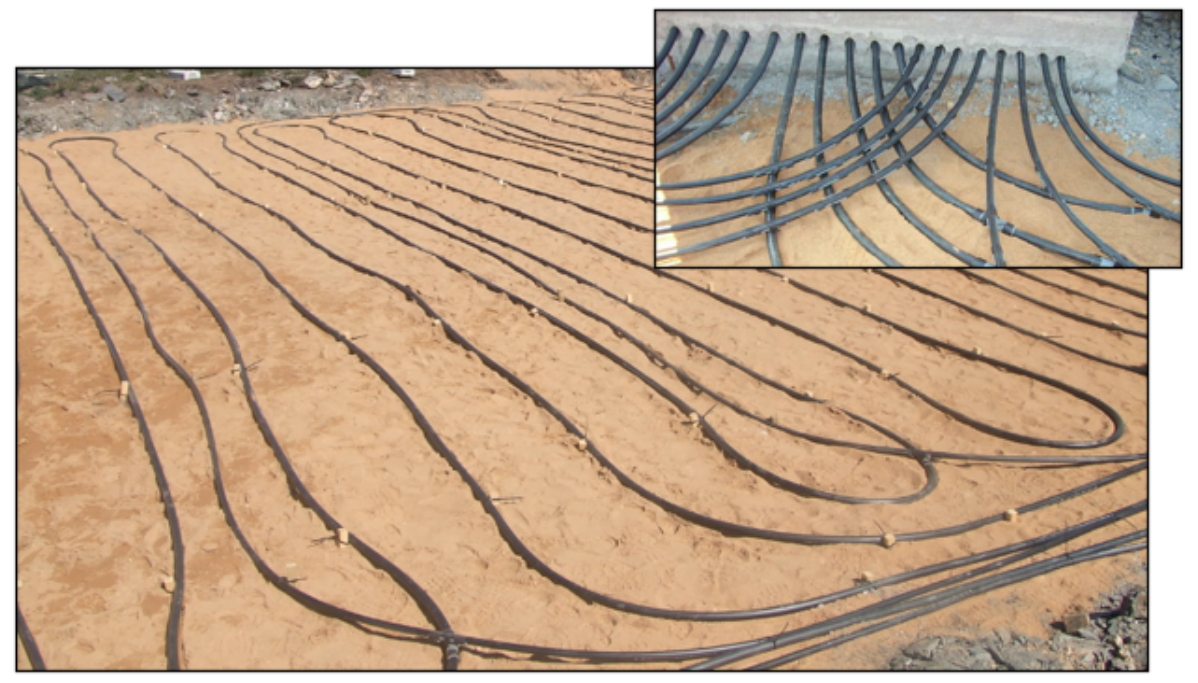

Fig. 5. Installation of the horizontal exchanger

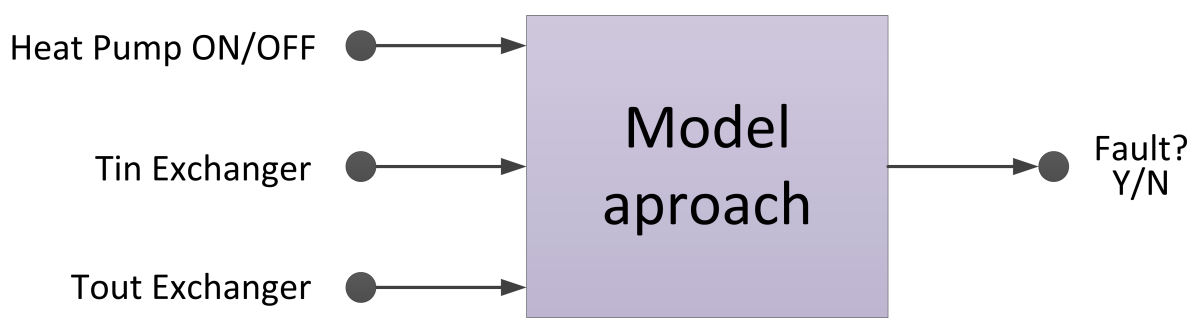

Fig. 6. Model approach

- If the Heat Pump is on, the difference between temperatures is going to increase at first time (see figure 8, into the frame).

- At certain time when the Heat Pump turn off, and between 30 and 40 minutes after that, the difference between temperatures decreases (see figure 8 , out the frame).

When the Heat Pump is off during a long time, the corresponding data are not taking into account. The dataset is obtained when the Heat Pump is in operation, and it turns off while temperatures do not achieved the steady state.

The initial dataset contains 52705 samples, and after discarding the non representative data, with the rules explained before, the data set contains 13612 samples.

\subsection{Classification techniques considered to create the model}

This section describes the classification techniques used to create the model. 


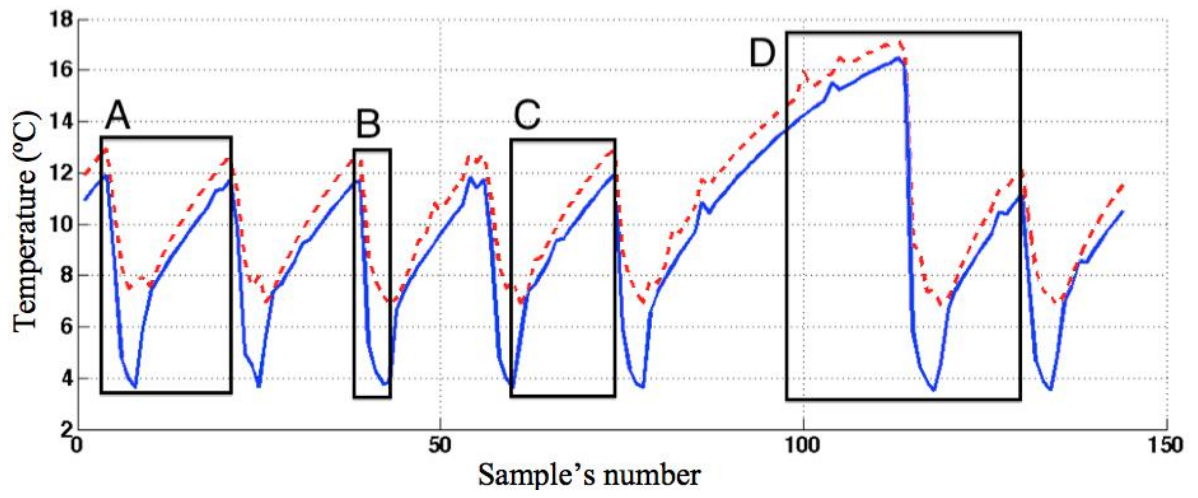

Fig. 7. One day of running cycles

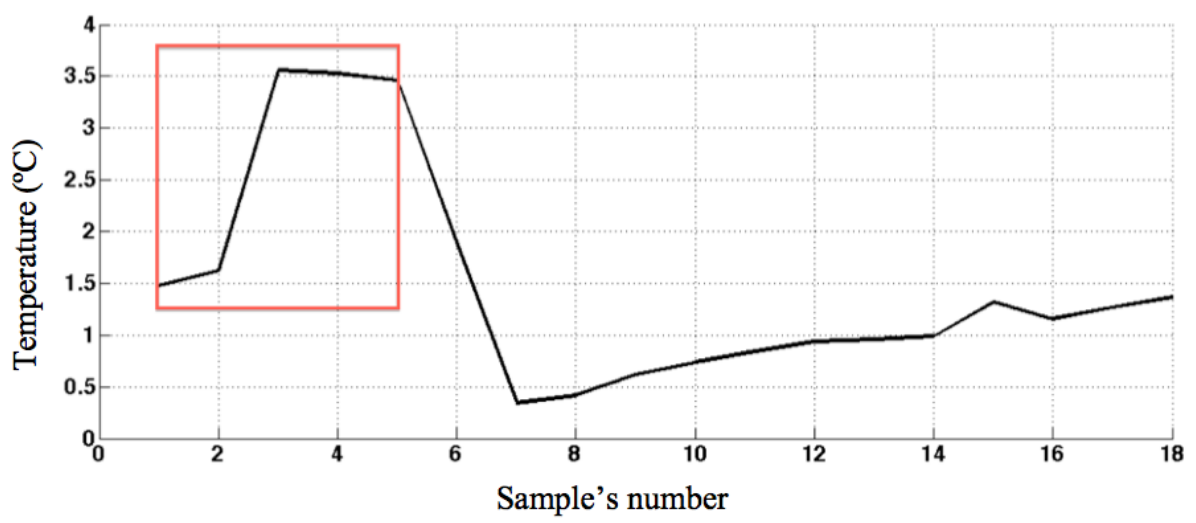

Fig. 8. Ratio between input and output of the Heat Pump

Fishers Linear Discriminant Analysis FLDA. This technique is used for reduction the dimension on a high-dimensional data project. The reduction achieves a low-dimensional space, where all the classes are separated $[17,18]$. FLDA create hyperplanes to discriminate the class as a result of analyzing the training data.

J48 learning algorithm . A decision tree is approach with this method, and there are the most common approaches in machine learning [19-21]. The decision trees are used to classify the data into different groups, depending of the variables used in training [19]. The decision trees were obtained by using the J48 algorithm $[19,22,23]$. J48 algorithm has better performance in most circumstances than other algorithms [23] This algorithm in based on an entropy calculation to develop the decision tree. Entropy is the probable information based on the partitioning into subcategories according to attribute. The clarity 
on the subcategory partitions achieve the greatest advantage. The feature with the greatest entropy reduction is chosen as the test attribute for the present node.

A multilayer perceptron (MLP) [19, 24]. The architecture on the ANN must be carefully selected to achieve the best results. In this study several activation function have been tested.

\section{Results}

The results of the classification is shown in table 1 . The performance of the classification techniques is obtained using the following parameters: Sensitivity (SE), Specificity (SPC), Positive Prediction Value (PPV), Negative Prediction Value (NPV) and Accuracy (ACC). The equations to calculate these parameters are shown in equations 2 to 6 respectively. Where, TP are the samples where there are no failures, $\mathrm{TN}$ are the samples where there are failures, and the model classify the samples in a good way. And, FP are the samples where there are failures, FN are the samples where there are no failures, but the model classifies the samples in a wrong way.

$$
\begin{gathered}
S E=\frac{T P}{T P+F N} \\
S P C=\frac{T N}{T N+F P} \\
P P V=\frac{T P}{T P+F P} \\
N P V=\frac{T N}{T N+F N} \\
A C C=\frac{T P+T N}{T P+T N+F P+F N}
\end{gathered}
$$

The dataset has been increased by including one hour of real time measurements. When the system acquires samples in real time, it saves the parameters every second. During this time of fast acquisition, it has been generated some typical anomalies in this type of systems. It was simulated a fluid leak in the system, an obstruction in a pipe, a partial failure in the exchanger...

The dataset has been divided in two groups; one for training (70\%, 12019 samples), and other to test the classification techniques (30\%, 5151 samples). Table 1 shows the confusion matrix, and the performance parameters that were explained before (equations 2 to 6 ). The actual data are the real classification of the data, and the predicted data are the classification output of the algorithms. 


\begin{tabular}{|c|c|c|c|c|c|c|}
\hline & \multicolumn{2}{|c|}{ FLDA } & \multicolumn{2}{|c|}{$\mathrm{J} 48$} & \multicolumn{2}{|c|}{ MLP } \\
\hline & $\begin{array}{l}\text { No Failure } \\
\text { (actual) }\end{array}$ & $\begin{array}{l}\text { Failure } \\
\text { (actual) }\end{array}$ & $\begin{array}{l}\text { No Failure } \\
\text { (actual) }\end{array}$ & $\begin{array}{l}\text { Failure } \\
\text { (actual) }\end{array}$ & $\begin{array}{l}\text { No Failure } \\
\text { (actual) }\end{array}$ & $\begin{array}{l}\text { Failure } \\
\text { (actual) }\end{array}$ \\
\hline $\begin{array}{l}\text { No Failure } \\
\text { (predicted) }\end{array}$ & $\begin{array}{l}2431 \\
47.19 \% \\
\end{array}$ & $\begin{array}{l}467 \\
9.07 \%\end{array}$ & \begin{tabular}{|l|}
3572 \\
$69.35 \%$ \\
\end{tabular} & \begin{tabular}{|l|}
163 \\
$3.16 \%$
\end{tabular} & $\begin{array}{l}3815 \\
74.06 \%\end{array}$ & $\begin{array}{l}50 \\
0.97 \%\end{array}$ \\
\hline \begin{tabular}{|l|} 
Failure \\
(predicted)
\end{tabular} & \begin{tabular}{|l|}
1621 \\
$31.47 \%$ \\
\end{tabular} & \begin{tabular}{|l|}
632 \\
$12.27 \%$ \\
\end{tabular} & $\begin{array}{l}479 \\
9.30 \% \\
\end{array}$ & $\begin{array}{l}937 \\
18.19 \% \\
\end{array}$ & \begin{tabular}{|l|}
269 \\
$5.22 \%$ \\
\end{tabular} & $\begin{array}{l}1017 \\
19.74 \% \\
\end{array}$ \\
\hline $\mathrm{SE}$ & \multicolumn{2}{|c|}{0.6000} & \multicolumn{2}{|c|}{0.8818} & \multicolumn{2}{|c|}{0.9341} \\
\hline $\mathrm{SPC}$ & \multicolumn{2}{|c|}{0.5751} & \multicolumn{2}{|c|}{0.8518} & \multicolumn{2}{|c|}{0.9531} \\
\hline PPV & \multicolumn{2}{|c|}{0.8389} & \multicolumn{2}{|c|}{0.9564} & \multicolumn{2}{|c|}{0.9871} \\
\hline NPV & \multicolumn{2}{|c|}{0.2805} & \multicolumn{2}{|c|}{0.6617} & \multicolumn{2}{|c|}{0.7908} \\
\hline $\mathrm{ACC}$ & \multicolumn{2}{|c|}{0.5946} & \multicolumn{2}{|c|}{0.8754} & \multicolumn{2}{|c|}{0.9381} \\
\hline
\end{tabular}

Table 1. Confusion matrix

\section{Conclusions}

With the novel model approach, it is possible to know when the geothermal exchanger of an installation based on a Heat Pump is failing. Very good results have been obtained in general terms. With this approach based on intelligent techniques working as a classification system, it is possible to predict malfunction states.

As can be seen in the results section, the best classification is achieved with MLP, where the percentage of classification accuracy is near to $94 \%$. Models created with other classification techniques also achieve good results as J48 algorithm with an accuracy of $87.5 \%$, however FLDA algorithm do not allow to achieve good result. The best detection failures only has an accuracy of $59.5 \%$.

Future work will be based on the application of on-line anomaly detection, with the aim to adapt the model to the progressive changes of the system. These changes can occur due to several reasons like the wear or the dirt.

\section{Acknowledgments}

This research is partially supported by the Spanish Ministry of Economy and Competitiveness under project TIN2010-21272- C02-01 (funded by the European Regional Development Fund), SA405A12-2 from Junta de Castilla y León. This work was also supported by the European Regional Development Fund in the IT4Innovations Centre of Excellence project (CZ.1.05/1.1.00/02.0070).

\section{References}

1. Langley, B.C.: Heat Pump Technology, 3rd Edition. Prentice Hall, Upper Saddle River (2002)

2. Sauer, H.J., Howell, R.H.: Heat Pump Systems. Wiley-Interscience, New York (1983)

3. Kakac, S., Liu, H.: Heat Exchangers: Selection, Rating and Thermal Design, 2nd Edition. CRC Press, Boca Raton, FL (2002) 
4. Rezaei, A.B., Kolahdouz, E.M., Dargush, G.F., Weber, A.S.: Ground Source Heat Pump Pipe Performance with Tire Derived Aggregate International Journal of Heat and Mass Transfer, 55(11-12): 2844-2853 (2012)

5. Lee, C.K.: Effects of multiple ground layers on thermal response test analysis and ground-source heat pump simulation. Applied Energy, 88(12): 4405-4410 (2011)

6. Sanner, B., Karytsas, C., Mendrinos, D., Rybach, L.: Current Status of Ground Source Heat Pumps and Underground Thermal Energy Storage in Europe. Geothermics, 32(4-6): 579-588 (2003)

7. Tarnawski, V.R., Leong, W.H., Momose, T., Hamada, Y.: Analysis of Ground Source Heat Pumps with Horizontal Ground Heat Exchangers for Northern Japan. Renewable Energy, 34(1): 127-134 (2009)

8. Omer, A.M.: Ground-Source Heat Pumps Systems and Applications. Renewable and Sustainable Energy Reviews, 12(2): 344-371 (2008)

9. Banks, D.: An Introduction to Thermogeology: Ground-Source Heating and Cooling. Wiley/Blackwell, Oxford (2008)

10. Isermann, R.: Fault-Diagnosis Systems: An Introduction from Fault Detection to Fault Tolerance. Springer, Germany (2006)

11. Isermann, R.: Fault-Diagnosis Applications: Model-Based Condition Monitoring: Actuators, Drives, Machinery, Plants, Sensors, and Fault-tolerant Systems. Springer, Germany (2011)

12. Hsu, W.Y.: Continuous EEG Signal Analysis for Asynchronous BCI Application. International Journal of Neural Systems, 21(04): 335-350 (2011)

13. Nozari, H.A., Shoorehdeli, M.A., Simani, S., Banadaki, H.D.: Model-based robust fault detection and isolation of an industrial gas turbine prototype using soft computing techniques. Neurocomputing, 91: 29-47 (2012)

14. Khan, S.A., Daachi, B., Djouani, K.: Application of fuzzy inference systems to detection of faults in wireless sensor networks. Neurocomputing, 94: 111-120 (2012)

15. Gryllias, K.C., Antoniadis, I.A.: A Support Vector Machine Approach Based on Physical Model Training for Rolling Element Bearing Fault Detection in Industrial Environments. Engineering Applications of Artificial Intelligence, 25(2): 326-344 (2012)

16. Tornil-Sin, S., Ocampo-Martinez, C., Puig, V., Escobet, T.: Robust Fault Detection of Non-Linear Systems Using Set-Membership State Estimation Based on Constraint Satisfaction. Engineering Applications of Artificial Intelligence, 25(1): 1-10 (2012)

17. Koç, M., Barkana, A.: A new solution to one sample problem in face recognition using FLDA. Applied Mathematics and Computation, 217(24): 10368-10376 (2011)

18. Calvo-Rolle, J.L., Casteleiro-Roca, J.L., Quintián, H., Meizoso-Lopez, M.C.: A hybrid intelligent system for PID controller using in a steel rolling process. Expert Systems with Applications, 40(13): 5188-5196 (2013)

19. Parr, O.: Data Mining Cookbook. Modeling Data for Marketing, Risk, and Customer Relationship Management. John Wiley \& Sons, Inc. New York (2001)

20. Duda, R.O., Hart, P.E., Stork, D.G.: Pattern Classification. John Wiley \& Sons, Inc. Canada (2001)

21. Khan, R., Hanbury, A., Stöttinger, J., Bais, A.: Color based skin classification. Pattern Recognition Letters, 33(2): 157-163 (2012)

22. Frank, E., Witten, I.: Data Mining: Practical Machine Learning Tools and Techniques, 2nd Edition. Morgan Kaufmann (2005)

23. Rokach, L., Maimon, O.: Data Mining with Decision Trees: Theory and Applications. World Scientific Publishing, USA (2008)

24. Alpaydin, E.: Introduction to Machine Learning. The MIT Press, Oxford (2009) 